\title{
Psychopathology symptoms in a sample of female cosmetic surgery patients
}

Citation for published version (APA):

Mulkens, S., Bos, A., Uleman, R., Muris, P. E. H. M., Mayer, B., \& Velthuis, P. (2012). Psychopathology symptoms in a sample of female cosmetic surgery patients. Journal of Plastic Reconstructive and Aesthetic Surgery, 65(3), 321-327. https://doi.org/10.1016/j.bjps.2011.09.038

Document status and date:

Published: 01/01/2012

DOI:

10.1016/j.bjps.2011.09.038

Document Version:

Publisher's PDF, also known as Version of record

Document license:

Taverne

Please check the document version of this publication:

- A submitted manuscript is the version of the article upon submission and before peer-review. There can be important differences between the submitted version and the official published version of record.

People interested in the research are advised to contact the author for the final version of the publication, or visit the DOI to the publisher's website.

- The final author version and the galley proof are versions of the publication after peer review.

- The final published version features the final layout of the paper including the volume, issue and page numbers.

Link to publication

\footnotetext{
General rights rights.

- You may freely distribute the URL identifying the publication in the public portal. please follow below link for the End User Agreement:

www.umlib.nl/taverne-license

Take down policy

If you believe that this document breaches copyright please contact us at:

repository@maastrichtuniversity.nl

providing details and we will investigate your claim.
}

Copyright and moral rights for the publications made accessible in the public portal are retained by the authors and/or other copyright owners and it is a condition of accessing publications that users recognise and abide by the legal requirements associated with these

- Users may download and print one copy of any publication from the public portal for the purpose of private study or research.

- You may not further distribute the material or use it for any profit-making activity or commercial gain

If the publication is distributed under the terms of Article $25 \mathrm{fa}$ of the Dutch Copyright Act, indicated by the "Taverne" license above, 


\title{
Psychopathology symptoms in a sample of female cosmetic surgery patients
}

\author{
Sandra Mulkens ${ }^{a, *}$, Arjan E.R. Bos ${ }^{a}$, Richard Uleman ${ }^{b}$, Peter Muris ${ }^{a, b}$, \\ Birgit Mayer $^{\mathrm{b}}$, Peter Velthuis ${ }^{\mathrm{c}}$
}

a Maastricht University, Maastricht, The Netherlands

${ }^{\mathrm{b}}$ Erasmus University Rotterdam, Rotterdam, The Netherlands

' Velthuis Clinics, Eindhoven, The Netherlands

Received 13 August 2011; accepted 23 September 2011

\section{KEYWORDS \\ Body dysmorphic disorder (BDD); Body image; Cosmetic surgery; Psychopathology}

\begin{abstract}
Summary Objective: During the past decades, cosmetic surgery has become increasingly popular. People with certain psychopathology disorders, for example, body dysmorphic disorder (BDD), are dissatisfied with their physical appearance, and a significant number try to receive cosmetic medical treatment for their complaints. It seems relatively easy for them to receive this type of surgery, despite the fact that it has no or even adverse effects on the symptoms. The present study aimed to investigate the psychological condition and especially the presence of psychopathological symptoms such as BDD in cosmetic surgery patients.

Methods: Questionnaires about body image dissatisfaction, symptoms of BDD and psychopathology in general and satisfaction about surgery were sent to patients who had been treated in a large cosmetic surgery clinic.

Results: Of the patients who replied, $86 \%$ were pleased with the outcome of the cosmetic procedure. Further, $21-59 \%$ of these former patients scored higher on questionnaires of body image dissatisfaction and psychopathological symptoms than a norm group from the general population. When differentiating the group on the basis of BDD symptomatology, it appeared that the high BDD symptomatic group displayed significantly worse outcome on all measurements. That is, high BDD symptomatic patients were more dissatisfied about the result of surgery, exhibited higher levels of psychopathology, and had lower self-esteem than the low symptomatic BDD patients.

Conclusion: These findings clearly suggest that the evaluation of the psychological condition and motivation of the candidate patient might be a valuable addition to the standard procedure in cosmetic medical treatment settings.

(c) 2011 British Association of Plastic, Reconstructive and Aesthetic Surgeons. Published by Elsevier Ltd. All rights reserved.
\end{abstract}

\footnotetext{
* Corresponding author. Maastricht University, Department of Clinical Psychological Science, PO Box 616, 6200 MD Maastricht, The Netherlands. Tel.: +31 43 3884052; fax: +31433884196.

E-mail address: s.mulkens@maastrichtuniversity.nl (S. Mulkens).
} 


\section{Introduction}

Cosmetic surgery has become increasingly popular. In 2009, 12.5 million procedures were carried out in the United States. ${ }^{1}$ This number includes both classical surgical methods (such as liposuction and rhinoplasty), making up about 1.5 million procedures, as well as new, non-surgical cosmetic procedures, good for nearly 11 million procedures. ${ }^{2}$ Between 2000 and 2009, cosmetic procedures have increased with nearly $70 \%,{ }^{1}$ which is largely accounted for by these new techniques.

From the patients' point of view, the most important reason for undergoing cosmetic surgery is body dissatisfaction, their bodily appearance constituting an important component of their self-esteem. ${ }^{3}$ Body image refers to the way people perceive their bodily appearance ${ }^{4,5}$ and is composed of several components, of which actual physical appearance is an important one. ${ }^{5}$ Sarwer et al. ${ }^{6}$ introduced a theoretical model of the relationship between body image and cosmetic surgery in which two basic elements - body image valence and body image value - play a central role. ${ }^{7}$ Body image valence refers to the importance of body image to one's self-esteem, whereas body image value entails the degree to which one is (dis)satisfied with one's appearance. According to this model, people whose self-esteem highly depends on their appearance (high body image valence) and who have a significant body dissatisfaction (low body image value) will consider cosmetic surgery. ${ }^{6}$

People with body dysmorphic disorder (BDD) are extremely dissatisfied with their physical appearance. According to the Diagnostic and Statistical Manual of Mental Disorders, ${ }^{8}$ BDD is defined as a preoccupation with an imagined defect in one's appearance. Furthermore, the preoccupation causes clinically significant distress or impairment in social, occupational or other important areas of functioning. Any part of the body may be the focus of BDD, ${ }^{9}$ but the preoccupations mostly relate to one or more aspects of the face or body such as skin, hair and nose. ${ }^{10}$ Since patients with BDD are more or less convinced that the solution for their problem lies in changing their appearance, they may often be encountered in medical treatment settings. An investigation by Veale et al. ${ }^{11}$ indicated that $26 \%$ of 50 patients with BDD had undergone cosmetic surgery, whereas Hollander, Cohen and Simeon ${ }^{12}$ even reported a higher rate (40\%). Another study ${ }^{13}$ assessed medical treatment-seeking behavior in 250 adults with BDD. It appeared that $76.4 \%$ had sought and $66 \%$ indeed received some type of medical (e.g., dermatological, surgical and dental) treatment. Crerand, Phillips, Menard and Fay ${ }^{14}$ studied 200 patients with BDD and discovered that $71 \%$ had sought and $64 \%$ indeed received cosmetic medical treatment. Dermatological treatment was most often sought and received. Nevertheless, those treatments rarely led to the improvement of BDD symptoms. A French prospective study ${ }^{15}$ included 30 patients with minimal defect in appearance (of whom 12 had BDD), requesting cosmetic surgery. They found that five years after the surgery request, six out of the seven operated BDD patients still had BDD and that three non-BDD patients had developed BDD at follow-up.

Phillips et al. ${ }^{13}$ found that cosmetic treatments rarely improved BDD symptoms. The most frequent treatment outcome in their study was 'no change in overall BDD severity' (72\%). Overall BDD severity worsened in $16.3 \%$, whereas it improved in $11.7 \%$ of the individuals. Only $7.3 \%$ of all treatments led to both a decrease in concern about the treated body part and overall improvement in BDD. Generally, patients worried more about another body area, developed new appearance concerns, became more concerned about minor imperfections in the treated area or worried that an improved body part would become ugly again. Still, BDD patients' satisfaction rating of the surgery itself was quite high, which might explain surgeons' positive decisions to operate on these patients.

The estimated prevalence of BDD patients within cosmetic medical settings varies from $5 \%$ to $15 \%$ in the United States. ${ }^{16,3,9}$ A Brazilian study ${ }^{17}$ reports a prevalence of $14 \%$ in a cosmetic dermatology setting compared with $6.7 \%$ in a general dermatology setting. The first European study reported a prevalence rate of $9.1 \%$ in a cosmetic surgery setting. ${ }^{18} \mathrm{~A}$ Dutch study in the dermatology and plastic surgery clinics of an academic hospital detected 3-8\% BDD patients. ${ }^{19}$ A Dutch pilot study among nine dissatisfied cosmetic surgery patients ${ }^{20}$ found that the majority displayed clearly heightened scores on psychopathology questionnaires, including BDD. None of them had undergone a preoperative psychological screening. Taken together, a significant number of BDD patients try to receive cosmetic medical treatment and they often appear to slip through preoperative screenings, obtaining the desired surgery. Yet, these types of treatments fall short of expectations in BDD patients.

The present study sought to investigate the presence of psychopathological symptoms, especially BDD symptoms, in a sample of cosmetic surgery patients. We also wondered whether increased scores on BDD questionnaires were associated with less satisfaction about surgery, more body dissatisfaction and higher rates of psychopathology. To our knowledge, the different forms of psychopathology and their association with treatment (dis)satisfaction have been hardly investigated within cosmetic surgery patients. Research into these factors is important as it is essential to detect crucial psychological problems before surgery. To this end, we asked patients who had been treated by cosmetic surgery clinics in the Netherlands to fill out questionnaires about body image, BDD, psychopathology in general and satisfaction about surgery

\section{Method}

\section{Participants}

Questionnaires were randomly sent to 1000 clients who had surgery in the past 5 years in one of the four Velthuis Clinics in the Netherlands and who had given consent for future approach. One-hundred and thirty-five individuals (127 females) returned the questionnaires. As there were only eight male responders, the main analyses will be carried out among only the female participants. Mean age was 45.4 years $(S D=11.8$; range $21-79)$. Mean time since their most recent surgery was 2.4 years $(S D=1.6$, range $0-5$ years). The mean amount of cosmetic procedures was 1.5 $(S D=0.9$; range $1-5): 66.1 \%$ had undergone one procedure 
in their whole life, $21.3 \%$ had two procedures and $11 \%$ had received three procedures or more. The question remained unanswered by $1.6 \%$. Table 1 shows the general characteristics and the type of (most recent) cosmetic surgery of these patients. Because of privacy reasons, we had no insight into the data of the non-responders.

\section{Questionnaires}

\section{Background variables}

These questions concerned sex, age, marital status, ethnicity, education, length, weight, time since latest cosmetic procedure, reason for the cosmetic procedure, satisfaction about the procedure, total amount of procedures ever and potential rejection(s) for cosmetic surgery.

\section{RSE}

Global self-esteem was measured by the Rosenberg SelfEsteem Scale (RSE) ${ }^{21}$ which contains 10 items to be scored on a four-point scale (1-4). A higher score means a more positive self-esteem. Scores below 21 indicate low selfesteem. ${ }^{22}$ Cronbach's alpha in the present study is 0.88 .

\section{MAQ}

My Appearance Questionnaire ${ }^{23,24}$ is a validated Dutch questionnaire that investigates to what extent individuals are (dis)satisfied with 31 body parts (part 1) and the behavioural and cognitive correlates of satisfaction about appearance (part 2). Part 2 was used in this study and

Table 1 General characteristics of the female research population.

\begin{tabular}{ll}
\hline Mean (sd) & Females $(\mathrm{N}=125)$ \\
\hline Age & $45.4(11.8)$ \\
Current BMI & $22.1(2.6)$ \\
Highest BMI ever & $23.7(3.5)$ \\
Lowest BMI ever & $19.4(1.9)$ \\
Total amount of procedures & $1.5(0.93)$ \\
Education ${ }^{\text {a }}$ & \\
Low & $29.4 \%$ \\
Medium & $41.3 \%$ \\
High & $29.4 \%$ \\
Marital status & \\
Married/living together & $80.3 \%$ \\
Divorced/widowed/single & $19.7 \%$ \\
Type of (most recent) cosmetic procedure \\
Breast correction (lifting/enlargement) \\
Eyelid correction & $45.6 \%$ \\
Liposuction/liposculpture & $71.2 \%$ \\
Face-lift (face, forehead, eyebrows) & $5.6 \%$ \\
Nose correction & $3.2 \%$ \\
Other facial & $5.6 \%$ \\
Other body & $1.6 \%$ \\
\hline
\end{tabular}

a Education: low education; elementary education, prevocational education, and lower general secondary education; medium education; vocational training, higher secondary education/pre-university education; high education; higher applied education, university. consists of 16 items to be rated on a five-point scale (1-5). Examples are: "I feel sad because of my appearance," and "I avoid looking in mirrors". Research indicates that it is able to discriminate between BDD patients and healthy individuals. Cronbach's alpha in the current study is 0.83 .

\section{SCL-90}

The Symptom Checklist $-90^{25}$ is a reliable and valid Dutch multidimensional self-report symptom questionnaire. It provides an estimation of experienced pathology in eight domains: phobic anxiety, anxiety, depression, somatisation, obsessive-compulsive problems, interpersonal sensitivity, hostility and sleeping problems. The internal consistency is high (alphas in the present study ranging from 0.70 to 0.89 ).

\section{BDDE-SR}

The Dutch Body Dysmorphic Disorder Examination SelfReport $^{26}$ (translated by the first author with permission) indicates the existence of BDD symptomatology. It contains three parts. The first part assesses body parts of greatest concern, the second part assesses the behaviours that patients carried out to improve their body part of greatest concern (e.g., cosmetic surgery) and the third part contains 28 questions, to be answered on a seven-point scale $(0-6)$. These questions include avoidance, cognitive, emotional and perceptual issues related to the body part of greatest concern over the past 28 days. The internal consistency of the English questionnaire is high (alpha $=0.94)$, just like the test-retest reliability $(r=0.90) .{ }^{27}$ Cronbach's alpha in the present study was 0.92 .

\section{Procedure}

Ethical approval for this study was obtained from the Ethical Committee at Erasmus University Rotterdam. Velthuis Clinics randomly selected 1000 patients who had undergone cosmetic surgery during five consecutive years and who had given consent for future approach. The questionnaires were sent to potential participants, including a stamped return envelope. An accompanying letter explained that Velthuis Clinics, Maastricht University and Erasmus University Rotterdam collaborated in investigating the wellbeing of former cosmetic surgery patients. After 2 weeks, a reminder letter was sent out.

\section{Operating procedures in Velthuis Clinics}

Intake for surgical procedures in the Velthuis Clinics is carried out by the plastic surgeon and a nurse, and is set to 30 min standard (40 min for breast enlargements). They discuss the patient's wishes and examine the technical possibilities. Before the intake, patients fill out questionnaires about medical history.

\section{Data reduction and analysis}

After exploration of general characteristics of our sample, we calculated Pearson correlations between the several questionnaires' scores. Second, mean scores on the several questionnaires within the present population were calculated and compared to population norm scores. To this end, 
the percentage of participants scoring above the clinical cut-off scores was calculated for each questionnaire and subscale separately. Next, individuals with high BDD symptomatoloy scores (i.e., above the clinical cut-off score for the BDDE-SR) were compared with individuals with low/ normal BDDE-SR scores on measures of psychopathology symptoms, self-esteem, rejection for surgery in the past and satisfaction about surgery.

\section{Results}

First, we examined the percentage of individuals who were dissatisfied about the cosmetic surgery. It appeared that $86 \%$ of our total sample were happy with the result at the time of the surgery, 9\% was unhappy, while $5 \%$ did not answer this question. With regard to current satisfaction with the result of the surgery, $79.3 \%$ were still happy, whereas $12.6 \%$ were currently unhappy and $8.1 \%$ did not answer this question. Only $6.7 \%$ of our sample reported that they had ever been refused for cosmetic surgery. The majority, $91.1 \%$, was never rejected, whereas $2.2 \%$ did not answer this question.

As shown in Table 2, correlations among various questionnaire scores were moderate to high. Not surprisingly, the correlation between the MAQ and the BDDE-SR was robust, $r(121)=0.59(p<0.001)$, indicating that they tap similar constructs. The association between the SCL-90 and the BDDE-SR was 0.67, indicating a strong positive relationship between BDD symptoms and general psychopathology. The associations between various questionnaires and the RSE were negative ( $r$ 's between 0.36 and 0.41), indicating that higher levels of psychopathological symptoms were accompanied by lower levels of selfesteem.

In Table 3, mean scores for the respective questionnaires are shown. Obviously, 22-59\% of the study sample obtained relatively high scores (higher than the clinical norm score) on the questionnaires interrogating body image dissatisfaction (BDDE-SR and MAQ, respectively) and psychopathology in general (SCL-90). With regard to global self-esteem, this sample did surprisingly well; only $3 \%$ scored below the population mean.

The individuals scoring above the BDDE-SR cut-off score (i.e., 38) were compared with those scoring below this cut-off with regard to their scores on the other questionnaires and their surgery satisfaction scores. There appeared to be 27 high BDD symptomatic women $(M=59.5 ; \quad S D=17.7 ;$ range $41-108)$ and 94 low $B D D$ symptomatic women $(M=17.4 ; S D=8.7$; range $0-36)$. From six individuals, BDDE-SR scores were not complete. Thus, 121 individuals were included (see Table 4). High and low BDD symptomatic females did not differ with respect to age and current BMI. However, high BDD females differed significantly from low BDD females on all other measurements. Not surprisingly, they differed on the MAQ scores, with high scorers being less satisfied with their bodies. Furthermore, high BDD symptomatics had lower self-esteem, and more psychopathology in general, indicated by the SCL-90. Moreover, they were significantly more often rejected for surgery in the past (23\% vs. $3 \%)$. Finally, high BDD symptomatics were more often dissatisfied about the result of cosmetic surgery, both at the time of surgery and currently.

\section{Discussion}

The present study explored the psychological condition of cosmetic surgery patients and especially the presence of psychopathologies such as BDD. We also wondered whether high BDD symptomatic individuals differ from low symptomatic individuals with regard to surgery satisfaction, and overall psychological functioning. In general, $86 \%$ of the participants reported to be pleased with the direct outcome of the cosmetic procedure and $79.3 \%$ were still satisfied, which is a satisfactory percentage for the clinic.

Quite a number of the respondents clearly displayed higher scores on indices of psychological (dys)functioning. That is, between $21 \%$ and $59 \%$ scored above clinical cut-off scores for the SCL-90, the BDDE-SR and the MAQ. A critical point that can be raised about this observation pertains to the retrospective study nature: It is possible that psychopathology has developed after the cosmetic surgery. Likewise, the respondents' surgical experience might have affected their test scores. For example, dissatisfaction with the surgery might have resulted in negative test responses. Still, for (symptoms of) a disorder like BDD this is unlikely, as it usually develops in adolescence and people generally have their appearances changed as a result of BDD instead of BDD being the consequence. ${ }^{13,15}$ Nevertheless, a prospective study into the results of surgery is needed to solve this problem. Future research in which cosmetic surgery patients are screened preoperatively and followed up for several years after surgery may investigate the effectiveness and consequences of cosmetic surgery over the long term. This may also help to establish predictors for

Table 2 Intercorrelations between the several questionnaires.

\begin{tabular}{lllll}
\hline & BDDE-SR & MAQ & RSE & SCL-90 \\
\hline BDDE-SR & $1(n=121)$ & $0.59^{*}(n=119)$ & $-0.39^{*}(n=121)$ & $0.68^{*}(n=119)$ \\
MAQ & - & $1(n=133)$ & $-0.36^{*}(n=125)$ & $0.53^{*}(n=122)$ \\
RSE & - & - & $1(n=135)$ & $-0.41^{*}(n=124)$ \\
SCL-90 Total score & - & - & - & $1(n=124)$ \\
\hline
\end{tabular}

${ }^{*} p<0.001$.

Note: BDDE-SR, Body Dysmorphic Disorder Examination Self-Report; MAQ, My Appearance Questionnaire; RSE, Rosenberg Self-Esteem Scale; SCL-90, Symptom Checklist-90. 
Table 3 Means (SDs) and ranges per questionnaire and percentage of the participants scoring above clinical cut-off scores.

\begin{tabular}{|c|c|c|c|c|}
\hline & $N$ & Mean (SD) & Range & $\begin{array}{l}\text { \% Above/below }{ }^{\mathrm{a}} \text { average } \\
\text { population norm score }\end{array}$ \\
\hline MAQ & 125 & $38.5(8.5)$ & $21-59$ & $44 \%$ \\
\hline BDDE-Q & 121 & $26.8(20.9)$ & $0-108$ & $22 \%$ \\
\hline SCL-90 Total & 124 & $125.6(32.5)$ & $90-282$ & $36 \%$ \\
\hline SCL-90 Phobic anxiety & 124 & $8.1(2.4)$ & $6-23$ & $32 \%$ \\
\hline SCL-90 Anxiety & 124 & $13.2(4.4)$ & $10-33$ & $31 \%$ \\
\hline SCL-90 Depression & 124 & $22.9(7.2)$ & $16-51$ & $39.5 \%$ \\
\hline SCL-90 Somatization & 124 & $18.2(5.8)$ & $11-42$ & $35 \%$ \\
\hline SCL-90 Obsessive-compulsive & 124 & $13.4(4.4)$ & $9-30$ & $28 \%$ \\
\hline SCL-90 Interpersonal sensitivity & 124 & $25.4(7.4)$ & $17-55$ & $31 \%$ \\
\hline SCL-90 Hostility & 124 & $7.6(2.3)$ & $6-23$ & $58.9 \%$ \\
\hline SCL-90 Sleeping problems & 124 & $5.3(2.7)$ & $2-14$ & $55.6 \%$ \\
\hline RSE & 127 & $33.5(5.7)$ & $7-40$ & $3 \%^{\mathrm{a}}$ \\
\hline
\end{tabular}

a For RSE, higher scores indicate a higher global self-esteem, so scores below average indicate a pathological condition.

success or failure of cosmetic surgery and to develop detection methods for psychologically unsuitable patients.

High BDD scorers were found to display significantly worse outcomes with regard to all measurements, except for current BMI. Thus, individuals, who scored above the population cut-off, were significantly more often dissatisfied about the result of surgery both at the time of surgery and also currently. Furthermore, they obtained higher psychopathology scores on all subscales of the SCL-90 and had a significant lower self-esteem than the non-symptomatic BDD group. Moreover, almost a quarter of the high BDD individuals had ever been rejected for cosmetic surgery, as opposed to only $3 \%$ in the low symptomatic group. This supports the idea that BDD symptomatic individuals do not belong in a cosmetic treatment setting.

Considering the above, it seems important for cosmetic surgeons and other medical caregivers to recognise BDD patients within their population. However, there is a lack of knowledge about psychiatric disorders in cosmetic surgeons ${ }^{28}$ and time and money for enhanced screenings are unavailable. Various studies indeed indicate that preoperative psychological screening is hardly carried out. $^{28}$ It would be advantageous if knowledge about (screening for) psychopathology and recognition of body image disorders would be more integrated in the education and training of cosmetic surgeons. Despite the increasing number of plastic surgeons who acknowledge and recognise $\mathrm{BDD}$ and related disorders, there has been relatively very little attention for psychopathological symptoms and BDD in candidate cosmetic surgery patients. Psychological and/ or psychiatric knowledge of surgeons is usually limited to what is obtained from their medical education. In the Netherlands, some time is devoted to psychiatry in the basic medical education. In the present study, there was

Table 4 Comparison of low and high BDD symptomatic individuals on psychopathology measures, surgery rejection, and satisfaction with cosmetic surgery.

\begin{tabular}{lccc}
\hline Mean (SD) & Low & High & $t / \chi 2$ \\
\hline Age & $45.7(11.0)$ & $45.8(13.6)$ & $\mathrm{ns}$ \\
Current BMI & $21.97(2.44)$ & $22.73(3.19)$ & $-1.3 \mathrm{~ns}$ \\
MAQ & $36.6(7.1)$ & $45.5(8.6)$ & $-5.5^{* * *}$ \\
RSE & $34.3(5.4)$ & $30.4(5.7)$ & $3.2^{* *}$ \\
SCL-90 Total & $115.1(18.8)$ & $161.1(43.8)$ & $-7.9^{* * *}$ \\
SCL-90 Phobic anxiety & $7.4(1.2)$ & $10.3(4.0)$ & $-5.9^{* * *}$ \\
SCL-90 Anxiety & $12.1(2.7)$ & $17.2(6.4)$ & $-6.0^{* * *}$ \\
SCL-90 Depression & $20.8(4.5)$ & $30.5(9.7)$ & $-7.3^{* * *}$ \\
SCL-90 Somatization & $16.9(4.6)$ & $22.4(7.1)$ & $-4.8^{* * *}$ \\
SCL-90 Obsessive-compulsive & $12.2(3.3)$ & $3.3(5.8)$ & $-5.8^{* * *}$ \\
SCL-90 Interpersonal sensitivity & $23.2(4.7)$ & $9.1(3.7)$ & $-7.3^{* * *}$ \\
SCL-90 Hostility & $7.1(1.5)$ & $7.4(3.5)$ & $-4.1^{* * *}$ \\
SCL-90 Sleeping problems & $4.8(2.1)$ & $23.1 \%$ & $-5.0^{* * *}$ \\
Ever rejected for surgery & $3.3 \%$ & $21.7 \%$ & $11.3^{* *}$ \\
Dissatisfaction about result at & $5.5 \%$ & $29.2 \%$ & $6.1^{*}$ \\
$\quad$ time of surgery & & & $6.3^{*}$ \\
Current dissatisfaction about & $9.3 \%$ & & \\
$\quad$ result & & & \\
\hline$* * * P \leq 0.001 ; * * P \leq 0.01 ; * P \leq 0.05$. & & &
\end{tabular}


30-40 min of intake time available, where the surgeon and the nurse assess whether the patient's wish and presentation of the 'problem' is realistic and recognisable. They use this as a standard for the assessment of a potential existence of BDD. Meanwhile, given that $66 \%$ of BDD patients have received cosmetic surgery anyway, ${ }^{13}$ and the estimations of candidate cosmetic surgery patients actually suffering from BDD being $5-15 \%,{ }^{3,9,16-20}$ plus the clues that cosmetic surgery might not help, this compels us to think about smarter screenings.

A potential solution for cosmetic surgeons could be to screen all potential patients with a short questionnaire and work closely together with psychologists for second opinions whenever desirable. In the United Kingdom, Veale et al. ${ }^{29}$ have constructed a short and easy-to-use screening instrument for cosmetic procedures. Another possibility is to use the BDDE-SR or another BDD questionnaire. A psychological consultation could also be a part of the cosmetic surgery intake. Of course, these types of regulations and screening procedures might give raise to a debate about free will and violations of one's right to self-determination. However, the main goal is to offer patients the best-available treatment. In the case of BDD, the best-available treatment is cognitivebehavioural therapy. ${ }^{30}$

The present study knows limitations. On the basis of these data, no official BDD diagnoses can be made, since the suitable diagnostic tool is a DSM-IV interview. However, since we used reliable and valid psychometric instruments, this allows us to classify individuals according to possessing certain psychopathological symptoms that can be linked to formal diagnoses. Furthermore, we are unaware of the actual (past) appearance of the individuals and whether their BDD scores are based on perceived flaws or on objective 'bad looks'. Future studies may use preoperative photographs to assess the 'flaw' by independent raters. Finally, we have no information about the representativeness of the current sample (our response rate being somewhat disappointing): unfortunately, it was not possible to compare the characteristics of the non-responders with those of the responders due to privacy restrictions. We therefore have no insight into the (reasons of) nonresponding in this study. We suspect, however, that time constraints are the most important reason, since the vast majority of the clientele of Velthuis Clinics are reasonably well-to-do individuals with busy lives and jobs. The selfselected population would then be a population who has found the time and energy to participate and not necessarily a worse or healthier population.

In conclusion, the present findings indicate that evaluation of the psychological condition and motivation of the candidate patient in cosmetic medical treatment settings is valuable. Therefore, medical practitioners might screen patients with (short) questionnaires and/or consider collaborating with psychologists. Furthermore, cosmetic surgeons might be trained to recognise potential problem patients and be informed about psychiatric disorders and their preferred psychological treatments.

\section{Conflict of interest}

There are no conflicts of interest reported for this study.

\section{Funding}

The departments of Clinical Psychological Science, Maastricht University and Clinical Psychology, Erasmus University Rotterdam, are thanked for their financial contribution to the study. These contributions covered the postal expenses for sending questionnaires to 1000 participants and for the free-of-charge return envelopes.

\section{References}

1. American Society of Plastic Surgeons (ASPS), www. plasticsurgery.org.

2. Sarwer DB, Crerand CE. Body image and cosmetic medical treatments. Body Image 2004;1:99-111.

3. Sarwer DB, Whitaker LA, Pertschuk MJ, Wadden TA. Body image concerns of reconstructive surgery patients: an underrecognized problem. Ann Plas Surg 1998;40:403-7.

4. Cash TF. Body image: past, present, and future. Body Image 2004;1:1-5.

5. Mowlawi A, Lille S, Andrews K, et al. Psychiatric patients who desire aesthetic surgery: identifying the problem patient. Ann Plas Surg 2000;44:97-106.

6. Sarwer DB, Wadden TA, Pertschuk MJ, Whitaker LA. The psychology of cosmetic surgery: a review and conceptualization. Clin Psychol Rev 1998;18:1-22.

7. Cash TF. Cognitive-behavioral perspectives on body image. In: Cash TF, Pruzinsky T, editors. Body image: a handbook of theory, research and clinical practice. New York: Guilford; 2002. p. 38-46.

8. American Psychiatric Association. Text revision. In: Diagnostic and statistical manual of mental disorders. 4th ed. Washington, DC: APA; 2000.

9. Veale D, De Haro L, Lambrou C. Cosmetic rhinoplasty in Body Dysmorphic Disorder. Brit J Plast Surg 2003;56:546-51.

10. Carroll DH, Scahill L, Phillips KA. Current concepts in Body Dysmorphic Disorder. Arch Psychiat Nurs 2002;16:72-9.

11. Veale D, Boocock A, Gournay K, et al. Body dysmorphic disorder: A survey of fifty cases. Brit J Psychiat 1996;169: 196-201.

12. Hollander E, Cohen LJ, Simeon D. Body dysmorphic disorder. Psychiat Ann 1993;23:359-64.

13. Phillips KA, Grant J, Siniscalchi J, Albertini RS. Surgical and nonpsychiatric medical treatment of patients with body dysmorphic disorder. Psychosomatics 2001;42:504.

14. Crerand CE, Phillips KA, Menard WM, Fay C. Nonpsychiatric medical treatment of body dysmorphic disorder. Psychosomatics 2005;46:549-55.

15. Tignol J, Biraben-Gotzamanis L, Martin-Guehl C, Grabot D, Aouizerate B. Body dysmorphic disorder and cosmetic surgery: evolution of 24 subjects with a minimal defect in appearance 5 years after their request for cosmetic surgery. Eur Psychiat 2007;22:520-4.

16. Ishigooka J, Iwao M, Suzuki M, Fukuyama $Y$, Murasaki $M$, Miura S. Demographic features of patients seeking cosmetic surgery. Psychiat Clin Neuros 1998;52:283-7.

17. Conrado LA, Hounie AG, Diniz JB, et al. Body dysmorphic disorder among dermatologic patients: Prevalence and clinical features. J Am Acad Dermatol 2010;63:235-43.

18. Aouizerate B, Pujol H, Grabot D, et al. Body dysmorphic disorder in a sample of cosmetic surgery applicants. Eur Psychiat 2003;18:365-8.

19. Vulink NC, Sigurdsson V, Kon M, Bruijnzeel-Koomen CA, Westenberg HG, Denys D. Body dysmorphic disorder in $3-8 \%$ of patients in outpatient dermatology and plastic surgery clinics. Ned Tijdschr Genees 2006;150:97-100. 
20. Mulkens S, Jansen A. Changing appearances: cosmetic surgery and body dysmorphic disorder. Netherlands Journal of Psychology 2006;62:34-41.

21. Rosenberg M. Society and the adolescent self-image. Princeton, NJ: Princeton University Press; 1965.

22. Rosenberg M. Conceiving the self. New York: Basic Books, Inc., Publishers; 1979.

23. Bouman TK. Mijn Uiterlijk Vragenlijst. Rijksuniversiteit Groningen; 1999.

24. Bouman TK. Measuring body dissatisfaction in BDD patients and non-clinical samples. Manuscript in preparation.

25. Arrindell WA, Ettema JHM. SCL-90. Handleiding bij een multidimensionele psychopathologie-indicator. Lisse: Swets en Zeitlinger; 1986.
26. Rosen JC, Reiter J. Development of the Body Dysmorphic Disorder examination. Behav Res Ther 1996;34:755-66.

27. Rosen JC, Reiter J. Instructions to users of the Body Dysmorphic Disorder Examination-Self Report (BDDE-SR). Unpublished manuscript; 1994.

28. Thomas JR, Sclafani AP, Hamilton M, MCDonough E. Preoperative identification of psychiatric illness in aesthetic facial surgery patients. Aesthet Plast Surg 2001;25:64-7.

29. Veale D, Ellison N, Werner TG, Dodhia R, Serfaty M, Clarke A. Development of a cosmetic procedure screening (COPS) questionnaire for Body Dysmorphic Disorder, submitted for publication.

30. Williams J, Hadjistavropoulos T, Sharpe D. A meta-analysis of psychological and pharmacological treatments for Body Dysmorphic Disorder. Behav Res Ther 2006;44:99-111. 